\title{
Article \\ Development of a Coordinate Measuring Machine-Based Inspection Planning System for Industry 4.0
}

\author{
Slavenko M. Stojadinovic ${ }^{1, *}$, Vidosav D. Majstorovic ${ }^{1} \mathbb{D}$, Adam Gąska $^{2}{ }^{\mathbb{D}}$, Jerzy Sładek ${ }^{2}$ \\ and Numan M. Durakbasa ${ }^{3}$
}

1 Department for Production Engineering, Faculty of Mechanical Engineering, University of Belgrade, Kraljice Marije 16, 11120 Belgrade, Serbia; vidosav.majstorovic@sbb.rs

2 Laboratory of Coordinate Metrology, Faculty of Mechanical Engineering, Cracow University of Technology, al. Jana Pawla II 37, 31-864 Cracow, Poland; adam.gaska@pk.edu.pl (A.G.); jerzy.sladek@pk.edu.pl (J.S.)

3 Department for Interchangeable Manufacturing and Industrial Metrology, Faculty of Mechanical and Industrial Engineering, Vienna University of Technology, Getreidemarkt 9/3113, BA09, 1060 Wien, Austria; numan.durakbasa@tuwien.ac.at

* Correspondence: sstojadinovic@mas.bg.ac.rs

check for updates

Citation: Stojadinovic, S.M.; Majstorovic, V.D.; Gąska, A.; Sładek, J.; Durakbasa, N.M. Development of a Coordinate Measuring MachineBased Inspection Planning System for Industry 4.0. Appl. Sci. 2021, 11, 8411. https://doi.org/10.3390/app 11188411

Academic Editors: Paolo Renna and Tiago M. Fernández-Caramés

Received: 1 July 2021

Accepted: 7 September 2021

Published: 10 September 2021

Publisher's Note: MDPI stays neutral with regard to jurisdictional claims in published maps and institutional affiliations.

Copyright: (c) 2021 by the authors. Licensee MDPI, Basel, Switzerland. This article is an open access article distributed under the terms and conditions of the Creative Commons Attribution (CC BY) license (https:// creativecommons.org/licenses/by/ $4.0 /)$.

\begin{abstract}
Industry 4.0 represents a new paradigm which creates new requirements in the area of manufacturing and manufacturing metrology such as to reduce the cost of product, flexibility, mass customization, quality of product, high level of digitalization, optimization, etc., all of which contribute to smart manufacturing and smart metrology systems. This paper presents a developed inspection planning system based on CMM as support of the smart metrology within Industry 4.0 or manufacturing metrology 4.0 (MM4.0). The system is based on the application of three AI techniques such as engineering ontology (EO), GA and ants colony optimization (ACO). The developed system consists of: the ontological knowledge base; the mathematical model for generating strategy of initial MP; the model of analysis and optimization of workpiece setups and probe configuration; the path simulation model in MatLab, PTC Creo and STEP-NC Machine software, and the model of optimization MP by applying ACO. The advantage of the model is its suitability for monitoring of the measurement process and digitalization of the measurement process planning, simulation carried out and measurement verification based on CMM, reduction of the preparatory measurement time as early as in the inspection planning phase and minimizing human involvement or human errors through intelligent planning, which directly influences increased production efficiency, competitiveness, and productivity of enterprises. The measuring experiment was performed using a machined prismatic workpiece $(\mathrm{PW})$.
\end{abstract}

Keywords: manufacturing metrology; industry 4.0; STEP-NC; inspection planning; CMM

\section{Introduction}

Industry 4.0, as a strategic initiative, aims to create smart factories where manufacturing technologies are upgraded and transformed into Internet of Things and cloud computing [1,2]. "The manufacturing industry is on the top of Industry 4.0, because it brings with it advanced technologies and techniques capable of rapidly and efficiently changing the products, processes and supply chains involved in every aspect of industry" [3]. The original definitions of Industry 4.0 are proposed in [4,5]. The definition contains several key words, such as advanced manufacturing and advanced metrology. This means that advanced manufacturing, or metrology, is the basis for the fourth industrial revolution. In the same context, the following terms are used worldwide: a smart factory (metrology), and intelligent manufacturing (metrology) [6]. "Industry 4.0 is also the digital transformation of manufacturing and related industries and value chain creation processes, based on intelligence of machines and processes for industry by information 
and communication technology" [7]. An evolution of production systems from Industry 2.0 through Industry 4.0 is presented in [8].

Within Industry 4.0, smart manufacturing systems are designed to respond in realtime for catering to the rapidly changing demands and conditions in the factory, the supply network, and customer needs. "Smart manufacturing is arriving and promises a future of mass-producing highly personalized products via responsive autonomous manufacturing operations at a competitive cost" [9]. "With the rapid growth of integrating ITs and operation technologies in the industry, significant efforts have been made to make manufacturing smart" [10]. Some key advantages of using smart manufacturing include higher quality products, improved productivity, safer plant floors, and improved energy efficiency. Those systems include machines, smart sensors, and robotic platforms, as well as the data necessary for monitoring, maintenance, and control of the production and measuring process.

If we perform a comparison between the development of technological systems and manufacturing metrology, according to [7,11], we can define the following facts: (i) a holistic measurement model applied as a smart system, and (ii) a CMM as a multi sensor system and CPS, making up today the basic framework of smart metrology model for Industry 4.0. "Based on cyber-physical system CPS and IoT technology, the flexible transformation of the manufacturing process to suit diverse customer manufacturing requirements is very possible, by make-to-order services" [12]. According to [13] "smart metrology is the implementation of a revised metrological function to make relevant decisions using AI techniques". The paper [14] discusses how the Industry 4.0 infrastructure can be used to collect and process data to obtain useful information about the in-line metrology process.

The basis of the "factory operating system for extending existing factories to Industry 4.0" [15] is the application of industrial innovations, primarily in the field of IT, with online communication and collaboration of manufacturers, customers and suppliers. From the standpoint of SMEs, according to [16], "flexibility, cost, efficiency, quality and competitive advantage" are found to be the key benefits to Industry 4.0 adoption. The outcome of research presented in [17] is a developed platform that will be referred to Industry 4.0 HUB for SMEs.

The paper [18] provides manufacturing execution system (MES) functionalities from I4.0-related requirements standpoint and an overview of development methods for those purposes. Today's trends for development and implementation, as well as the functions of MES in the context of Industry 4.0 are given in $[19,20]$.

When it comes to measurement strategies applicable for Industry 4.0 purposes, only strategies that offer automatic distribution of measurement points can be applied. All manual distribution strategies and non-analytical strategies are not applicable for this purpose. A very important element in choosing a strategy is also measurement uncertainty. In this paper, a modified Hammersley strategy was chosen precisely because of measurement uncertainty.

The contribution of this paper refers to the development of the manufacturing metrology 4.0 model as a support of the I4.0 concept based on the existing CP3M presented in $[6,7,21]$ and the application of AI techniques such as EO, ACO, and GA to optimize the $\mathrm{MP}$, the number of PW setups, as well as the configuration of the measuring head and probes. Testing of the developed model in a laboratory environment was performed on PW manufactured on machine tool LOLA HMC 500 and measured on CMM ZEISS UMM 500. The advantage of the model is its suitability for monitoring of the measurement process and digitalization of the measurement process planning, simulation carried out in MatLab, PTC Creo and STEP-NC Machine software and measurement verification based on virtual and real CMM UMM 500, reduction of the preparatory measurement time as early as in the inspection planning phase and minimizing human involvement or human errors through intelligent planning, which directly influences increased production efficiency, competitiveness, and productivity of enterprises. The novelty of the model mirrors in the overcoming of interoperability between different software for CMM programming by 
automatically generating a point-to-point path that can be used for any CMM software by further post-processing.

The paper is organized through the following main sections: (i) smart metrology and Industry I4.0, (ii) inspection features and ontology knowledge base, (iii) inspection planning model with mathematical model of initial MP, (iv) optimization models and (v) simulation of MP.

\section{Outline of the Concept}

The inspection planning system as a support of manufacturing metrology 4.0 (IP2SM4.0) covers all elements of planning execution of parts inspection on CMM, using the models and connections between them according to Figure 1:

- $\quad$ EO model for extraction of geometric features from IGES and STL file and define GD\&T of metrological feature of the PWs and integration by ontology knowledge base;

- $\quad$ ACO model for design of MP optimization as a first main part of IP2SM4.0;

- GA model for optimal part setup and probes optimization, as a second main part of IP2SM4.0;

- Mathematical model integrates distribution of the measurement points, accessibility and collision avoidance analysis;

- $\quad$ Simulation in MatLab (shown as a measurement path on Figure 1), PTC Creo and STEP-NC Machine and generation of an appropriate output file.

\section{INDUSTRY 4.0}

SMART FACTORY

SMART MANUFACTURING
Other elements

Other elements

SMART METROLOGY MODEL BASED ON CMM - SMART CMM

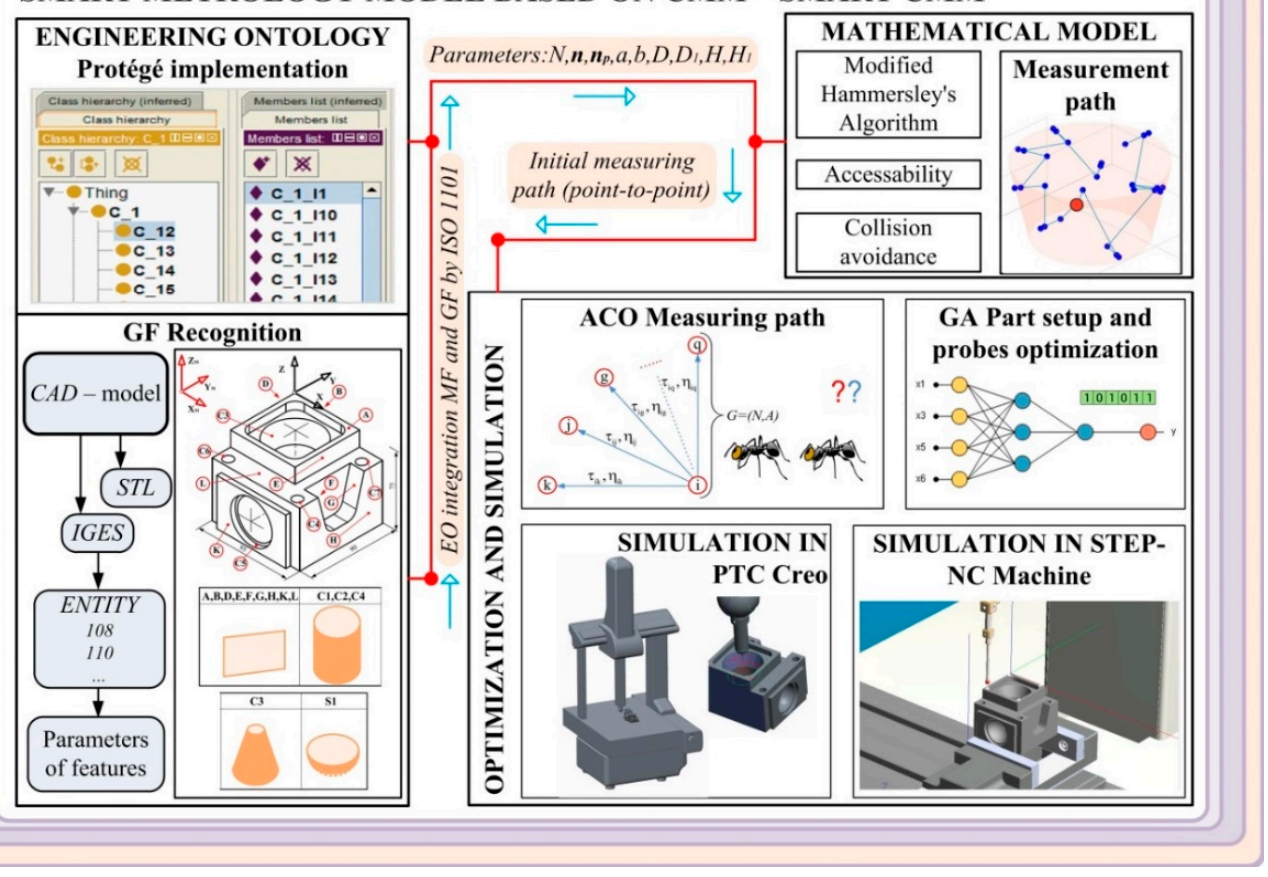

Figure 1. Outline of the concept.

Overall output IP2SM4.0 is an optimal MP for real CMM and elimination of human errors through intelligent planning and optimization of probe configuration and PW setup, which directly influences increased production efficiency, competitiveness, and productivity of enterprises. 
According to [22], manufacturing metrology consists of the following types of measurements: (i) shape, (ii) material, (iii) function, and (iv) electricity. It can conclude that Industry 4.0 model has all types of measurements, with the first component as the most represented for manufacturing. For that reason, the main focus in this paper is tolerance of these types of measurements and tolerance according to standard ISO 1101.

\section{Inspection Features and Engineering Ontology}

\subsection{Inspection Feature Modeling}

Inspection feature (IF) consists of one or more geometric features (GFs) and they represent a link between a standard type of tolerances and GFs that PWs consists of. A standard type of GFs such as planes, circles, cylinders, cones, truncated cones, hemispheres and truncated hemispheres are used for the generation and description of all IF types. Each GF is absolutely determined by the parameters in relation to the $\mathrm{CS}_{\mathrm{F}} \mathrm{O}_{\mathrm{F}} \mathrm{Y}_{\mathrm{F}} \mathrm{Z}_{\mathrm{F}}$. Parameters can be of the following type: coordinates $(\mathrm{X}, \mathrm{Y}, \mathrm{Z})$, diameter $(\mathrm{D}, \mathrm{D} 1)$ height $(\mathrm{H}, \mathrm{H} 1)$, width $(\mathrm{a})$, length (b), vector of a primitive $(\mathbf{n})$, parameter of the fullness of a feature $\left(\mathbf{n}_{\mathbf{p}}\right)$. Extraction of the GFs parameters from IGES file is possible based on the knowledge of its structure and is given in [23].

\subsection{Ontology Knowledge Base}

Assuming that GFs can be represented as EO classes and parameters of the IFs as properties of the classes, this chapter provides an ontological description of IFs and ontology knowledge base. EO components are defined as:

- Classes: represent GFs such as: point C_1, line C_2, circle C_3, ellipse C_4, plane C_5, sphere C_6, cylinder C_7, cone C_8 and torus C_9.

- Subclasses: GFs that participate in creating other primitives are EO subclasses: C_11, C_12, C_13, ... , C_19; C_52, C_53, C_54, C_57, C_58, C_59). e.g., C_52 represents the plane that participates in creating a line.

- Individuals: represent GFs defined by mentioned parameters. The example of individuals for class point is labeled as C_12_I1 and represents the point obtained as an intersection of straight lines.

- Properties: individual parameters represent EO properties as four types of properties: coordinates of points, normal vectors, diameter, and angle.

Implementation of the developed ontological description was carried out in software Protégé-OWL editor. OWL ontology includes description of classes, properties and individuals. Software Protégé is a free, open source ontology editor based on Java. Protégé implements a set of knowledge-modeling structures and actions that support the creation, visualization, and manipulation of ontologies in various representations of data formats [24].

According to $[23,25,26]$, the implementation of IFs in Protégé consists of modeling: (i) classes, (ii) class hierarchy, (iii) individuals, and (iv) classes and individuals' properties. Figure 2 shows part of the PW ontological structure decomposition (hierarchy of classes, hierarchy of object properties and hierarchy of data properties) into geometric features. Initially, the workpiece was decomposed into standard types of tolerances as defined by ISO 1101. 


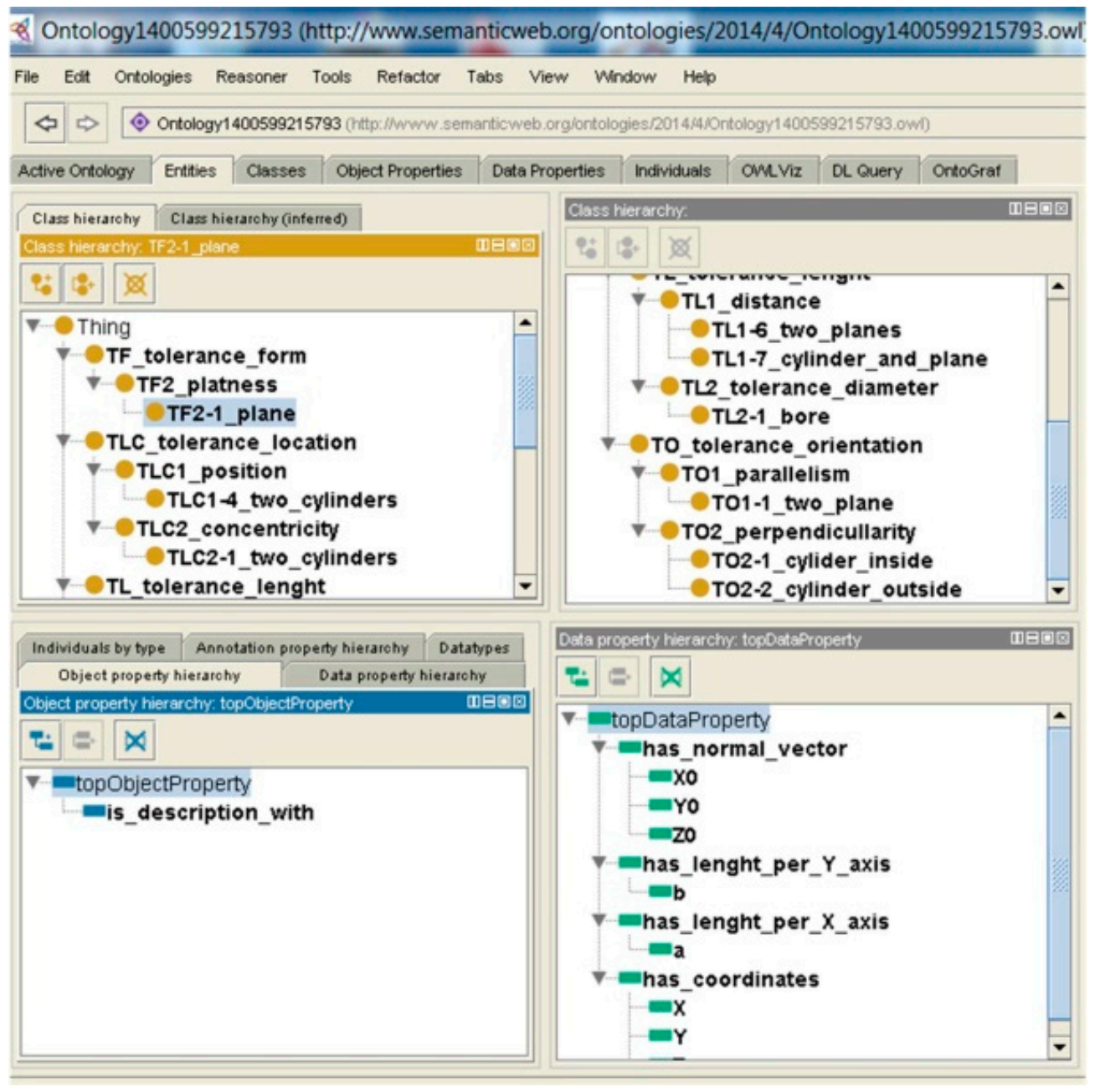

Figure 2. Ontology implementation in Protégé-OWL editor.

In this case, those are the tolerances of: length (TL), form (TF), orientation (TO) and location (TLC). These types of tolerances are downwards decomposed into specific types of tolerances defined by a standard as well. Adhering to this procedure is necessary because of linking specific tolerance types with tolerances that occur in practice. The next iteration is related to decomposition into upper-level types of tolerances-the types encountered in the technical drawing of the part.

According to the previously described model of the knowledge base, the tolerances of demo PW are reduced to GFs. In that case, all metrological features taking part in the creation of the part tolerance were included: TL, TF, TO and TLC (Figure 3). The TL according to ISO 1101 consists of four basic types of length tolerance (TL-1-61, TL-1-62, TL-1-62 and TL-1-7) and five diameter tolerances (TL-2-11, TL-2-12 TL-2-13 TL-2-14 and TL-2-15). The tolerance of form is TF-2-1, whereas the tolerances of orientation are denoted by TO-2-11, TO-2-12, TO-2-13, TO-2-14, TO-2-11 and TO-2-12. The tolerance of location is indicated by TLC1-4. 


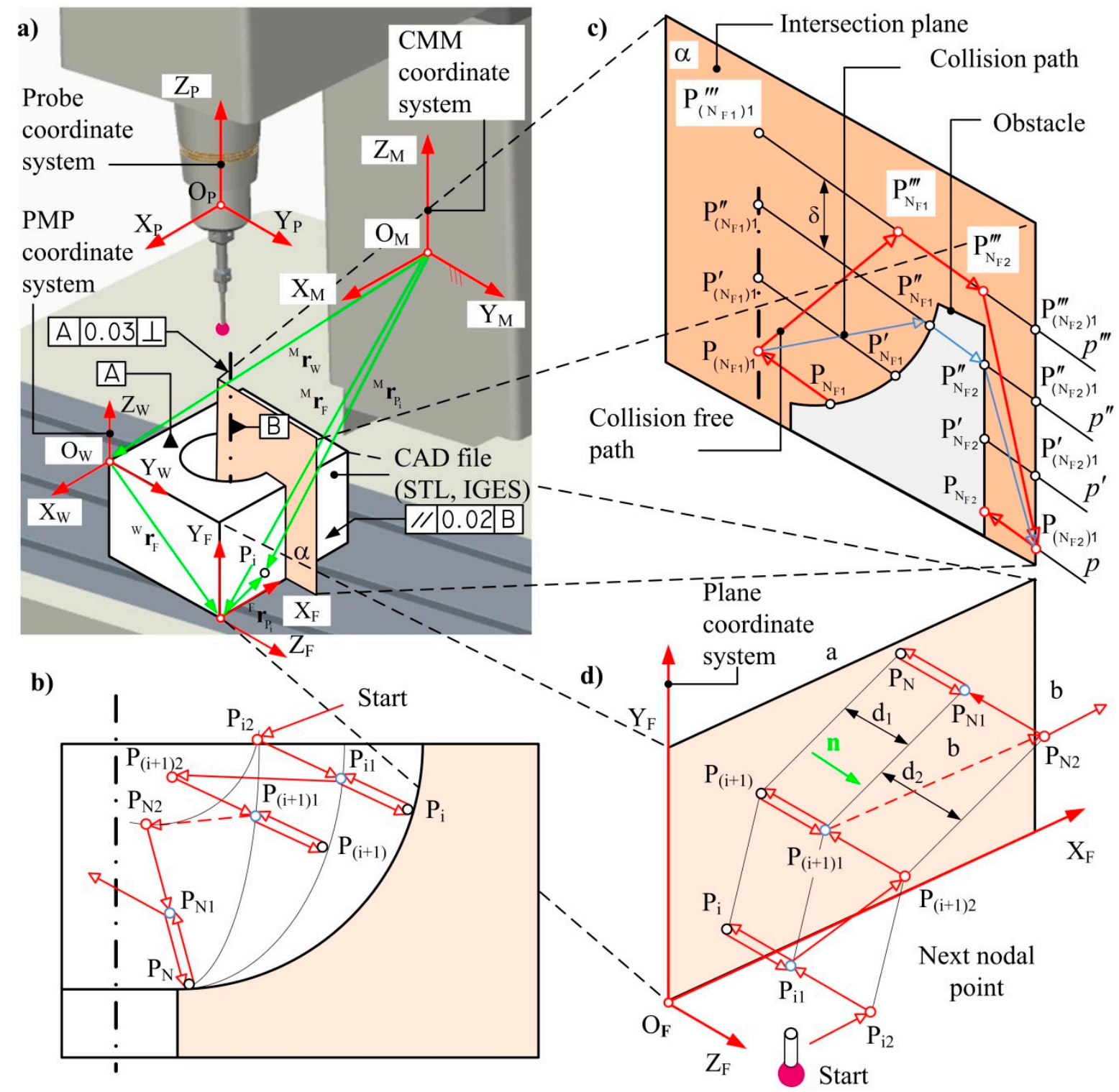

Figure 3. Mathematical model: (a) a PW and its tolerances, (b) initial MP for truncated sphere, (c) collision free path, (d) initial MP for plane.

The ontological base integrates tolerances and geometry in compliance with ISO 1101, and concretely for a specific PW it determines uniquely the values of IFs parameters.

\section{Inspection Planning Model}

The inspection planning model consists of the method of initial MP generating and analysis of PW setups and the configuration of sensors.

\subsection{Initial Measuring Path Generating}

The initial MP generating starts from the mathematical model presented in [27,28]. The model is adapted to the needs of the I4.0 concept that is basically related to the aspect of automatic generation of the MP. Primary benefit of the mathematical model is to create connections between $\mathrm{CSs}$ (Figure $3 \mathrm{a})$ such as probe $\left(\mathrm{O}_{\mathrm{P}} \mathrm{X}_{\mathrm{P}} \mathrm{Y}_{\mathrm{P}} \mathrm{Z}_{\mathrm{P}}\right), \mathrm{PW}\left(\mathrm{O}_{\mathrm{W}} \mathrm{X}_{\mathrm{W}} \mathrm{Y}_{\mathrm{W}} \mathrm{Z}_{\mathrm{W}}\right)$, features $\left(\mathrm{O}_{\mathrm{F}} \mathrm{X}_{\mathrm{F}} \mathrm{Y}_{\mathrm{F}} \mathrm{Z}_{\mathrm{F}}\right)$, and $\mathrm{CMM}\left(\mathrm{O}_{\mathrm{M}} \mathrm{X}_{\mathrm{M}} \mathrm{Y}_{\mathrm{M}} \mathrm{Z}_{\mathrm{M}}\right)$, as well as to generate an initial MP for each IF. According to Figure 3a, the basic Equation (1) of the model is:

$$
{ }^{\mathrm{M}} \mathbf{r}_{P_{\mathrm{i}}}={ }^{\mathrm{M}} \mathbf{r}_{\mathrm{W}}+{ }^{\mathrm{W}} \mathbf{r}_{\mathrm{F}}+{ }^{\mathrm{F}} \mathbf{r}_{\mathrm{P}_{\mathrm{i}}}={ }^{\mathrm{M}} \mathbf{r}_{\mathrm{F}}+{ }^{\mathrm{F}} \mathbf{r}_{\mathrm{P}_{\mathrm{i}}}
$$


where: ${ }^{\mathrm{W}} \mathbf{r}_{\mathrm{F}}$-GF system's position vector in the PW CS, ${ }^{\mathrm{F}} \mathbf{r}_{\mathrm{P}_{\mathrm{i}}}$-probe point's position vector in the GF CS, ${ }^{\mathrm{M}} \mathbf{r}_{\mathrm{W}}$-PW system's position vector in the CMM CS, ${ }^{\mathrm{M}} \mathbf{r}_{\mathrm{F}}-\mathrm{GF}$ (plane) system's position vector in the CMM CS.

As aforementioned, the role of a mathematical model is automatic distribution of measuring points per IF and generation of initial MP. Two sets of points generating of the initial path: (i) the measuring points and (ii) nodal points. Sampling strategy of those points for different GFs that make up a single IF is obtained by modifying Hamersley sequences presented in [28]. An example of equations of measuring points coordinates $\mathrm{P}_{\mathrm{i}}\left(\mathrm{s}_{\mathrm{i}}, \mathrm{t}_{\mathrm{i}}, \mathrm{w}_{\mathrm{i}}\right)$ in Cartesian CS for a plane and truncated hemisphere, according to $[27,28]$, is given as follows:

Plane:

$$
\begin{gathered}
s_{i}=\frac{i}{N} \cdot a \\
t_{i}=\left(\sum_{j=0}^{k-1}\left(\left[\frac{i}{2^{j}}\right] \operatorname{Mod} 2\right) \cdot 2^{-(j+1)}\right) \cdot b \\
w_{i}=0
\end{gathered}
$$

where: $\mathrm{a}[\mathrm{mm}]$ —distance per axis $\mathrm{x} ; \mathrm{b}[\mathrm{mm}]$ —distance per axis $\mathrm{y}$

Truncated hemisphere:

$$
\begin{gathered}
s_{i}=\sqrt{R^{2}-\left(\left(\sum_{j=0}^{k-1}\left(\left[\frac{i}{2^{j}}\right] \operatorname{Mod} 2\right) \cdot 2^{-(j+1)}\right) \cdot R\right)^{2}} \cdot \cos \left(\frac{i}{N} \cdot 360^{\circ}\right) \\
t_{i}=\sqrt{R^{2}-\left(\left(\sum_{j=0}^{k-1}\left(\left[\frac{i}{2^{j}}\right] \operatorname{Mod} 2\right) \cdot 2^{-(j+1)}\right) \cdot R\right)^{2}} \cdot \sin \left(\frac{i}{N} \cdot 360^{\circ}\right) \\
w_{i}=\left(\sum_{j=0}^{k-1}\left(\left[\frac{i}{2^{j}}\right] \operatorname{Mod} 2\right) \cdot 2^{-(j+1)}\right) \cdot\left(R-h_{1}\right)
\end{gathered}
$$

where $R[\mathrm{~mm}]$ is the radius and $h_{1}[\mathrm{~mm}]$ is the height of a truncated hemisphere. The set of nodal points implies two sub-sets $\mathrm{P}_{\mathrm{i} 1}\left(\mathrm{~s}_{\mathrm{i} 1}, \mathrm{t}_{\mathrm{i} 1}, \mathrm{w}_{\mathrm{i} 1}\right)$ and $\mathrm{P}_{\mathrm{i} 2}\left(\mathrm{~s}_{\mathrm{i} 2}, \mathrm{t}_{\mathrm{i} 2}, \mathrm{w}_{\mathrm{i} 2}\right)$, where is $\mathrm{i}=$ $0,1,2, \ldots,(N-1)$ and $N-$ number of sampling points. The points $P_{i 1}\left(x_{i 1}, y_{i 1}, z_{i 1}\right)$ presents points for the transition from fast to slow feed. The distance between points $P_{i 1}\left(x_{i 1}, y_{i 1}, z_{i 1}\right)$ and $P_{i}\left(x_{i}, y_{i}, z_{i}\right)$ is presented (Figure $3 d$ ) by $d_{1}$-slow feed probe path, and the distance between points $P_{\mathrm{i} 2}\left(\mathrm{x}_{\mathrm{i} 2}, \mathrm{y}_{\mathrm{i} 2}, \mathrm{z}_{\mathrm{i} 2}\right)$ and $\mathrm{P}_{\mathrm{i} 1}\left(\mathrm{x}_{\mathrm{i} 1}, \mathrm{y}_{\mathrm{i} 1}, \mathrm{z}_{\mathrm{i} 1}\right)$ is $\mathrm{d}_{2}$-rapid feed probe path.

According to $[27,28]$, coordinates of the nodal points $P_{i 1}\left(x_{i 1}, y_{i 1}, z_{i 1}\right)$ and $P_{i 2}\left(x_{i 2}, y_{i 2}, z_{i 2}\right)$ are defined from:

$$
\begin{aligned}
& \mathrm{x}_{\mathrm{i} 1}=\mathrm{x}_{\mathrm{P}_{\mathrm{i}} \mathrm{P}_{\mathrm{i} 1}}+\mathrm{x}_{\mathrm{i}}, \mathrm{y}_{\mathrm{i} 1}=\mathrm{y}_{\mathrm{P}_{\mathrm{i}} \mathrm{P}_{\mathrm{i} 1}}+\mathrm{y}_{\mathrm{i}}, \mathrm{z}_{\mathrm{i} 1}=\mathrm{z}_{\mathrm{P}_{\mathrm{i}} \mathrm{P}_{\mathrm{i} 1}}+\mathrm{z}_{\mathrm{i}}, \\
& \mathrm{x}_{\mathrm{i} 2}=\mathrm{x}_{\mathrm{P}_{\mathrm{i}} \mathrm{P}_{\mathrm{i} 2}}+\mathrm{x}_{\mathrm{i}}, \mathrm{y}_{\mathrm{i} 2}=\mathrm{y}_{\mathrm{P}_{\mathrm{i}} \mathrm{P}_{\mathrm{i} 2}}+\mathrm{y}_{\mathrm{i}}, \mathrm{z}_{\mathrm{i} 2}=\mathrm{z}_{\mathrm{P}_{\mathrm{i}} \mathrm{P}_{\mathrm{i} 2}}+\mathrm{z}_{\mathrm{i}} .
\end{aligned}
$$

where coordinates $x_{i}=s, y_{i}=t, z_{i}=w_{i}$ are actually coordinates of the measuring point $\mathrm{P}_{\mathrm{i}}\left(\mathrm{s}_{\mathrm{i}}, \mathrm{t}_{\mathrm{i}}, \mathrm{w}_{\mathrm{i}}\right)$, while other unknown coordinates are determined from the expression:

$$
\begin{gathered}
P_{\mathrm{i}} \overrightarrow{\mathrm{P}}_{\mathrm{i} 1}=\overrightarrow{n_{\mathrm{pi}}} \cdot \mathrm{d}_{1}=\mathrm{x}_{\mathrm{P}_{\mathrm{i}} \mathrm{P}_{\mathrm{i} 1}} \overrightarrow{\mathrm{i}}+\mathrm{y}_{\mathrm{P}_{\mathrm{i}} \mathrm{P}_{\mathrm{i} 1}} \overrightarrow{\mathrm{j}}+\mathrm{z}_{\mathrm{P}_{\mathrm{i}} \mathrm{P}_{\mathrm{i} 1} \overrightarrow{\mathrm{k}}} \\
\overrightarrow{\mathrm{P}}_{\mathrm{i}} \overrightarrow{\mathrm{P}}_{\mathrm{i} 2}=\overrightarrow{\mathrm{n}}_{\mathrm{pi}} \cdot\left(\mathrm{d}_{2}+\mathrm{d}_{1}\right)=\mathrm{x}_{\mathrm{P}_{\mathrm{i}} \mathrm{P}_{\mathrm{i} 2}} \overrightarrow{\mathrm{i}}+\mathrm{y}_{\mathrm{P}_{\mathrm{i}} \mathrm{P}_{\mathrm{i} 2}} \overrightarrow{\mathrm{j}}+\mathrm{z}_{\mathrm{P}_{\mathrm{i}} \mathrm{P}_{\mathrm{i} 2}} \overrightarrow{\mathrm{k}}
\end{gathered}
$$

where $\overrightarrow{n_{p i}}$ is the vector of fullness of GF.

Based on the STL file for the representation of PW shape, the tolerances of PW, the coordinates of the end point $\mathrm{P}_{\left(\mathrm{N}_{\mathrm{F} 1}\right)}$ of a feature truncated hemisphere and the coordinates of the start point $\mathrm{P}_{\left(\mathrm{N}_{\mathrm{F} 2}\right)}$ of a feature plane, the simplified principle of collision free path 
between PW and probe for example parallelism tolerance inspection is shown in Figure 3c. An obstacle to be overcome by the principle of collision avoidance is represented in the intersection plane $\alpha$ and refers to parallelism tolerance designated in Figure 3a. As can be seen, in this case, IF is the parallelism tolerance and is composed of two GFs (plane and truncated hemisphere).

The principle is iterative and consists of moving line $p$ for distance $\delta$ until the line became collision free (line segment $p$ ).

Overall travelled path [27] by a measuring probe in the inspection in $\mathrm{N}$ measuring points represents an initial MP of a measuring sensor and can be calculated as

$$
\begin{gathered}
\mathrm{D}_{\text {tot }}=\sum_{\mathrm{i}=0}^{\mathrm{N}-1}\left(\left|\mathrm{P}_{\mathrm{i} 2} \overrightarrow{\mathrm{P}}_{\mathrm{i} 1}\right|+2 \cdot\left|\overrightarrow{\mathrm{P}_{\mathrm{i} 1} \mathrm{P}_{\mathrm{i}} \mid}+\right| \overrightarrow{\mathrm{P}_{\mathrm{i} 1} \mathrm{P}_{(\mathrm{i}+1) 2}} \mid\right)+ \\
+\sum_{\mathrm{i}=1}^{\mathrm{P}}\left(\left|\mathrm{P}_{\mathrm{NF}_{1}} \overrightarrow{\mathrm{P}}_{\left(\mathrm{NF}_{1}\right) 1}\right|+\left|\mathrm{P}_{\left(\mathrm{NF}_{1}\right) 1} \overrightarrow{\mathrm{P}}^{\prime \prime \prime} \mathrm{NF}_{1}\right|+\left|\mathrm{P}^{\prime \prime \prime} \mathrm{NF}_{1} \overrightarrow{\mathrm{P}}^{\prime \prime \prime} \mathrm{NF}_{2}\right|+\left|\mathrm{P}_{\left(\mathrm{NF}_{2}\right) 1} \mathrm{P}_{\mathrm{NF}_{2}}\right|\right)
\end{gathered}
$$

where: $\mathrm{P}$-number of obstacles (transitions from one feature to another), $\left|\mathrm{P}_{\mathrm{i} 2} \overrightarrow{\mathrm{P}}_{\mathrm{i} 1}\right|$ rapid feed rate and 2. $\left|\overrightarrow{\mathrm{P}_{\mathrm{i} 1} \mathrm{P}_{\mathrm{i}}}\right|$ double travelled slow feed rate for the i-th point, and $\left|\mathrm{P}_{\mathrm{i} 1} \overrightarrow{\mathrm{P}}_{(\mathrm{i}+1) 2}\right|$ length of distance in probe's transition from previous $i$-th point to the next $(i+1)$ nodal point. Calculated coordinates of distributed points $(\mathrm{N}=10)$ for two unit $\mathrm{GFs}$ for parallelism tolerance, according to this methodology, are given in Table 1.

\begin{tabular}{|c|c|c|c|c|c|c|c|}
\hline & & \multicolumn{6}{|c|}{ Unit GF } \\
\hline \multicolumn{2}{|c|}{ Points and No. } & \multicolumn{3}{|c|}{ Plane } & \multicolumn{3}{|c|}{ Truncated Hemisphere } \\
\hline & & $X$ & $\mathbf{Y}$ & $\mathbf{Z}$ & $X$ & $Y$ & $\mathbf{Z}$ \\
\hline \multirow{10}{*}{$\mathrm{P}_{\mathrm{i}}$} & 1 & 0.0000 & 0.0000 & 0.0000 & 1.0000 & 0.0000 & 0.0000 \\
\hline & 2 & 0.1000 & 0.6641 & 0.0000 & 0.6049 & 0.4395 & 0.6641 \\
\hline & 3 & 0.2000 & 0.3281 & 0.0000 & 0.2919 & 0.8984 & 0.3281 \\
\hline & 4 & 0.3000 & 0.9922 & 0.0000 & -0.0386 & 0.1186 & 0.9922 \\
\hline & 5 & 0.4000 & 0.1563 & 0.0000 & -0.7991 & 0.5806 & 0.1563 \\
\hline & 6 & 0.5000 & 0.8203 & 0.0000 & -0.5719 & 0.0000 & 0.8203 \\
\hline & 7 & 0.6000 & 0.4844 & 0.0000 & -0.7078 & -0.5142 & 0.4844 \\
\hline & 8 & 0.7000 & 0.1484 & 0.0000 & -0.3056 & -0.9405 & 0.1484 \\
\hline & 9 & 0.8000 & 0.0625 & 0.0000 & 0.3084 & -0.9492 & 0.0625 \\
\hline & 10 & 0.9000 & 0.7266 & 0.0000 & 0.5559 & -0.4039 & 0.7266 \\
\hline \multirow{10}{*}{$\mathrm{P}_{\mathrm{i} 1}$} & 1 & 0.0000 & 0.0000 & 0.3333 & 0.9200 & 0.0000 & 0.0000 \\
\hline & 2 & 0.1000 & 0.6641 & 0.3333 & 0.5565 & 0.4043 & 0.6641 \\
\hline & 3 & 0.2000 & 0.3281 & 0.3333 & 0.2686 & 0.8265 & 0.3281 \\
\hline & 4 & 0.3000 & 0.9922 & 0.3333 & -0.0355 & 0.1092 & 0.9922 \\
\hline & 5 & 0.4000 & 0.1563 & 0.3333 & -0.7352 & 0.5341 & 0.1563 \\
\hline & 6 & 0.5000 & 0.8203 & 0.3333 & -0.5262 & 0.0000 & 0.8203 \\
\hline & 7 & 0.6000 & 0.4844 & 0.3333 & -0.6512 & -0.4731 & 0.4844 \\
\hline & 8 & 0.7000 & 0.1484 & 0.3333 & -0.2811 & -0.8653 & 0.1484 \\
\hline & 9 & 0.8000 & 0.0625 & 0.3333 & 0.2837 & -0.8733 & 0.0625 \\
\hline & 10 & 0.9000 & 0.7266 & 0.3333 & 0.5114 & -0.3716 & 0.7266 \\
\hline \multirow{10}{*}{$\mathrm{P}_{\mathrm{i} 2}$} & 1 & 0.0000 & 0.0000 & 1.0000 & 0.6000 & 0.0000 & 0.0000 \\
\hline & 2 & 0.1000 & 0.6641 & 1.0000 & 0.3629 & 0.2637 & 0.6641 \\
\hline & 3 & 0.2000 & 0.3281 & 1.0000 & 0.1751 & 0.5390 & 0.3281 \\
\hline & 4 & 0.3000 & 0.9922 & 1.0000 & -0.0231 & 0.0712 & 0.9922 \\
\hline & 5 & 0.4000 & 0.1563 & 1.0000 & -0.4794 & 0.3483 & 0.1563 \\
\hline & 6 & 0.5000 & 0.8203 & 1.0000 & -0.3431 & 0.0000 & 0.8203 \\
\hline & 7 & 0.6000 & 0.4844 & 1.0000 & -0.4247 & -0.3085 & 0.4844 \\
\hline & 8 & 0.7000 & 0.1484 & 1.0000 & -0.1834 & -0.5643 & 0.1484 \\
\hline & 9 & 0.8000 & 0.0625 & 1.0000 & 0.1850 & -0.5695 & 0.0625 \\
\hline & 10 & 0.9000 & 0.7266 & 1.0000 & 0.3335 & -0.2423 & 0.7266 \\
\hline
\end{tabular}

Table 1. Coordinates of distributed measuring and nodal points. 


\subsection{Analysis of PW Setups and Configuration of Sensors}

Inspection on a three-axis CMM such as ZEISS UMM 500 can be done from three orthogonal directions corresponding to the axes $\mathrm{X}, \mathrm{Y}$ and $\mathrm{Z}$. Thus, six directions can be derived corresponding to the axes of the machine $+X,-X,+Y,-Y,+Z$ and $-Z$. From the standpoint of access to the GF the term feature approach direction (FAD) is presented, while from the standpoint of probes the probe approach direction (PAD) is introduced [3]. The FADs, as shown in Figure 4a, define possible directions of access to the GF.

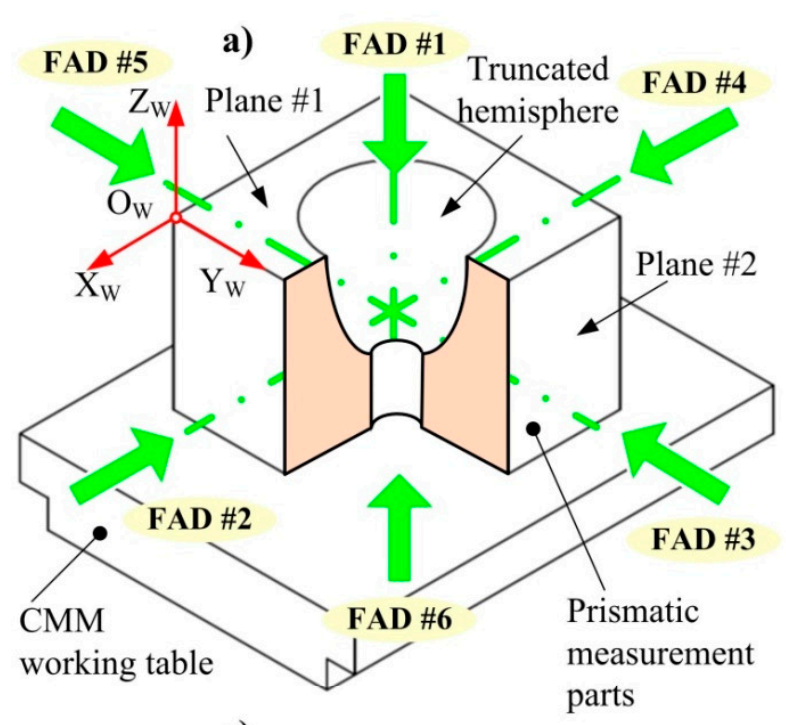

c)

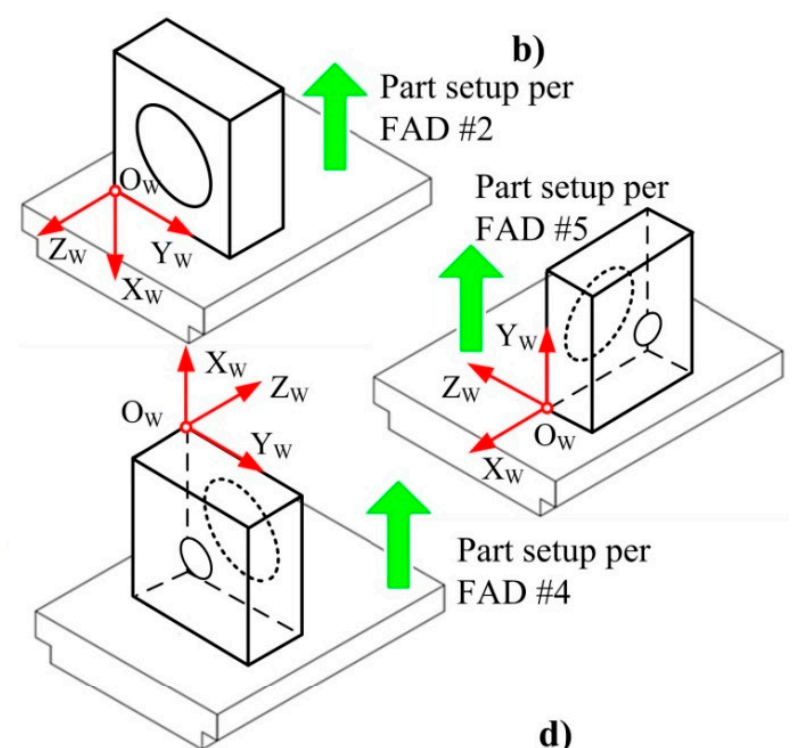

d)

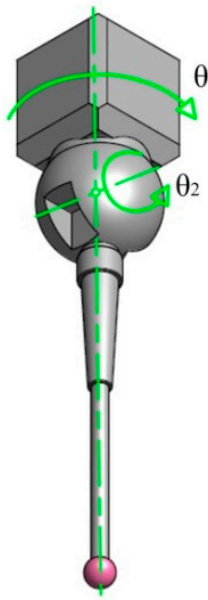

Figure 4. FADs and PADs for PW: (a) FADs for an example PW, (b) possible part setups per some FADs, (c) probe head, (d) PADs for star configuration of probes.

FADs are used to analyze the setup of the measuring part as it shown in Figure $4 \mathrm{~b}$. On the other side, PADs, as shown in Figure 4c,d, define the possible directions of the probe access. Due to the setup of the PW on the working table of CMM, one of the PADs is lost, so that the maximum number of PADs can be 5 .

\section{Optimization Models}

\subsection{Optimization of PW Setups and Probe Configuration}

Applying of the model GA is posibile if define the Boolean matrices of PW setup $\mathrm{S}$ and probe configuration $C$. The elements of the matrix $S$ are linked to the FADs and can be 0 or 1 . For example, according to Figure $4 a$, the element of the matrix takes the value 
because the truncated sphere can be accessed from FAD\#1. Similarly, the element of the matrix takes the value because the truncated sphere cannot be accessed from FAD \# 4 .

Analogous to the matrix $\mathrm{S}$, according to [3], the configuration matrix $\mathrm{C}$ is also filled to use the PADs. The number of rows of both matrices is equal to the number of GFs which are design IFs. In this case study, they are two types of tolerance (parallelism and perpendicularity) and three GFs, so the matrix $\mathrm{C}$ is as follows:

$$
\mathrm{C}=\left[\begin{array}{cccccc}
\text { PAD\#1 } & \text { PAD\#2 } & \text { PAD\#3 } & \text { PAD\#4 } & \text { PAD\#5 } & \text { PAD\#6 } \\
1 & 0 & 0 & 0 & 0 & 0 \\
1 & 1 & 1 & 1 & 1 & 1 \\
1 & 1 & 0 & 1 & 1 & 1
\end{array}\right] \begin{gathered}
\text { trun.sphere } \\
\text { plane\#1 } \\
\text { plane\#2 }
\end{gathered}
$$

Optimal solutions for the case of PW setup are obtained by GA model [3,27] and are represented by the zero-columns. Optimal solutions for the case of probe configuring (measuring heads) are also obtained by mentioned GA model and are represented by the one-columns. According to [3,27], GA consists of three main sections, as follows:

- initial population,

- fitness function,

- selection.

\subsubsection{Initial Population}

If introduce a new matrix $\mathrm{P}$, which represents the matrix of randomly defined rows of matrix $\mathrm{C}$ or $\mathrm{S}$, it can be defined as the GA initial population, and modified optimization algorithm $[27,29]$ can be applied, which has Boolean matrix for the initial population and optimal solution.

\subsubsection{Fitness Function}

According to [3], the principle of defining the fitness function has physical meaning that can read like this: possible approach directions (probe configuration) for a single PW setup become ultimate (optimal) only along the most represented directions. Thus, a new fitness function in the matrix form is

$$
\mathrm{F}=\left[\mathrm{F}_{1 \mathrm{ij}}\right]_{\mathrm{m} \times \mathrm{n}} \cdot\left[\mathrm{F}_{2 \mathrm{ij}}\right]_{\mathrm{m} \times \mathrm{n}}
$$

where:

$$
\begin{aligned}
& F_{1}=\left[F_{1 i j}\right]_{m \times n}=F_{1(i, j)}=\left[\sum_{i=1}^{m} c_{i j}\right], j=1,2, \ldots, n \\
& F_{2}=\left[F_{2 i j}\right]_{m \times n}=F_{2(i, j)}=\left[\sum_{j=1}^{n} c_{i j}\right], i=1,2, \ldots, m
\end{aligned}
$$

The first condition $\left(\mathrm{F}_{1}\right)$ is to take from each row of the initial population $\mathrm{P}$ matrix at least 1 unit and at most 5 units each. The second condition $\left(F_{2}\right)$ is that this unit is taken from the column, whose sum is maximum. This way, priority columns or columns whose sum is maximum, and less important columns or non-priority columns are extracted.

\subsubsection{Selection}

The selection matrix $\mathrm{W}$ in this method is modified and given in [3] by the expression (17)

$$
\mathrm{W}=\left[\mathrm{W}_{\mathrm{ij}}\right]_{\mathrm{m} \times 1}=\mathrm{W}_{(\mathrm{i}, \mathrm{j})}=\mathrm{W}_{\mathrm{ij}}((\mathrm{i}, \mathrm{j}) \in\{1,2, \ldots, \mathrm{m}, 1,2, \ldots, \mathrm{m}\} \times\{1\}), \mathrm{W}_{\mathrm{ij}} \in\{0,1\}
$$

Algorithm was tested for the following parameters: (1) $\mathrm{N}=\mathrm{m}=16$-population size, or the number of features for inspection, (2) $G=5$-genome size, (3) $S=100$-tournament size, (4) $G=1000-$ number of used genes and (5) $p_{p e r}=0.02-$ value of permutation probability. 


\subsection{Optimization of Initial Measuring Path}

As aforementioned, this planning system considered a model for optimizing the MP based on ants colony. The application of ACO in a coordinate metrology is based on the defining collision zones (Figure $5 \mathrm{a}, \mathrm{c}$ ) and solution of travelling salesmen problem (TSP), where the set of cities corresponds to the set of points of a minimal MP length.
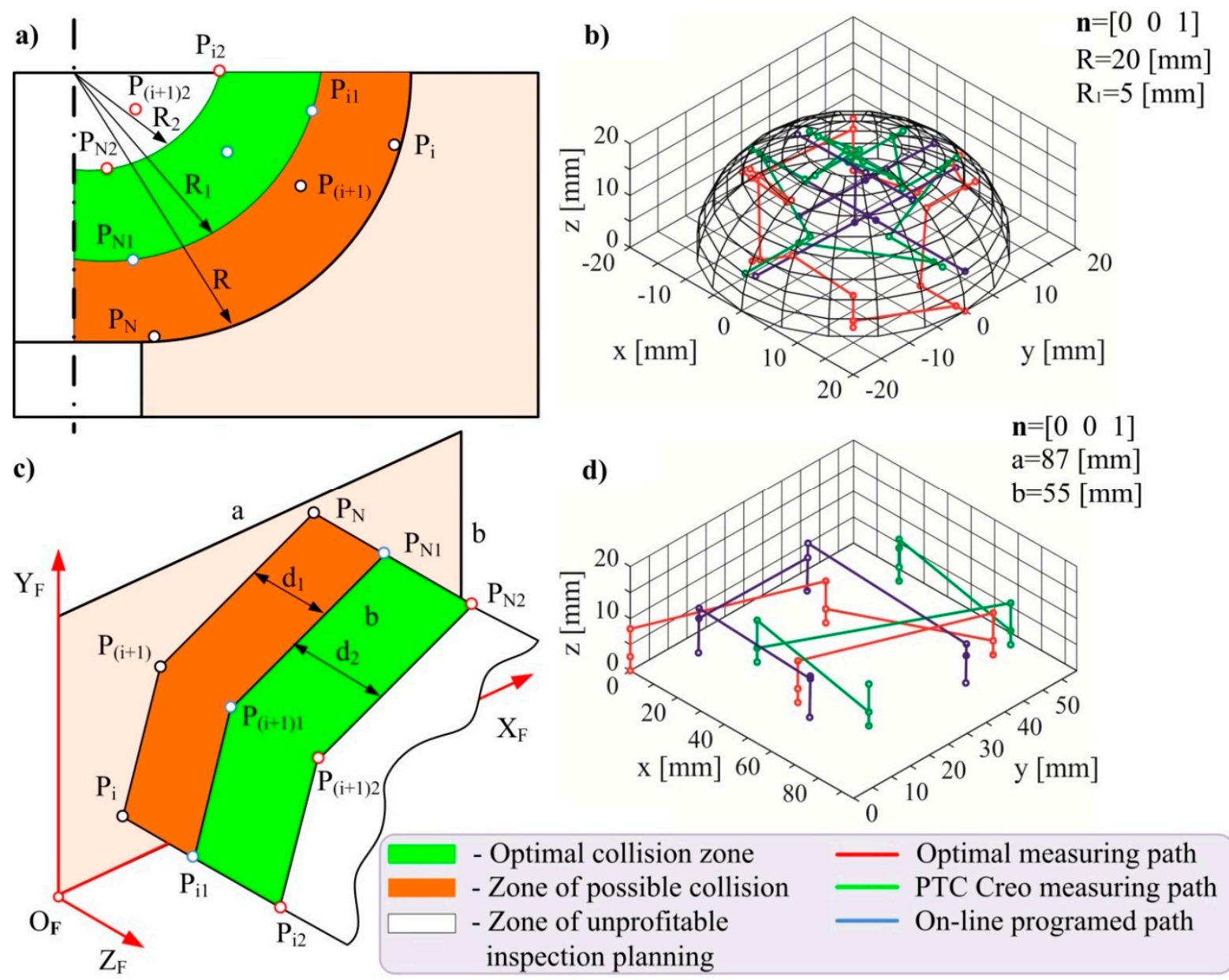

Figure 5. Collision zone and simulation paths: (a) truncated sphere collision zone, (b) simulation path for truncated sphere, (c) plane collision zone, (d) simulation path for plane. In order to solve Equation (18) and thus obtain the optimal path, it is necessary to solve TSP.

According to [30], ACO is based on Equation (18) for calculation of the point-to-point measuring probe path during measurement on $\mathrm{N}$ points:

$$
\min \left\{\mathrm{D}_{\text {tot }}\right\}=\mathrm{K}+\left\{\begin{array}{l}
\sum_{\mathrm{i}=0}^{\mathrm{N}-1} \quad\left(\min \left\{\left|\mathrm{P}_{\mathrm{i} 1} \overrightarrow{\mathrm{P}}_{(\mathrm{i}+1) 2}\right|\right\} \vee \min \left\{\left|\mathrm{P}_{\mathrm{i}(\mathrm{i}+1) \overrightarrow{\mathrm{P}}_{(\mathrm{i}+1) 2} \mid}\right|\right\} \vee \min \left\{\left|\mathrm{P}_{\mathrm{i} 1} \overrightarrow{\mathrm{P}}_{(\mathrm{i}+1) 1}\right|\right\} \vee\right. \\
\left.\left.\mathrm{P}_{\mathrm{i} 2} \overrightarrow{\mathrm{P}}_{(\mathrm{i}+1) 1} \mid\right\}\right)
\end{array}\right\}
$$

where $\mathrm{K}=\mathrm{N} \cdot\left(2 \cdot \mathrm{d}_{1}+\mathrm{d}_{2}\right)$ represents a constant lengths of MP, $\mathrm{d}_{1}=\left|\overrightarrow{\mathrm{P}_{\mathrm{i} 1} \mathrm{P}_{\mathrm{i}}}\right|$ and $\mathrm{d}_{2}=$ $\left|\vec{P}_{\mathrm{i} 2} \vec{P}_{\mathrm{i} 1}\right|$ as presented in the fourth chapter.

According to [30-32], "TSP can be represented by a complete weighted graph $\mathrm{G}=(\mathrm{N}, \mathrm{A})$ with $N$ being the set of nodes representing the cities, and A being the set of arcs. Each arc $(i, j) \in A$ is assigned a value (length) $d_{i j}$, which is the distance between cities $i$ and $j$, with 
$i, j \in N$. "The goal in TSP is to find a minimum length of Hamiltonian circuit of the graph where a Hamiltonian circuit is a closed path visiting each of the $n=|N|$ nodes of $G$ exactly once" $^{\prime \prime}[30,31]$, so that an optimal solution to the TSP is a permutation $\pi$ of the node indices $\{1,2, \ldots, n\}$.

The decision on which path is the shortest is obtained based on the criteria of the maximum amount of ants colony evaporated pheromones. For that it use the values of the weight coefficients $\tau_{\mathrm{ij}}$ and $\eta_{\mathrm{ij}}$. Coefficient $\eta_{\mathrm{ij}}$ represents the influence of the distance between two nodes of a graph, while $\tau_{\mathrm{ij}}$ is the probability that an ant leaving the node $\mathrm{i}$ visits the node $j$ as the next one.

The results of comparison based on this optimization model for three paths and two GFs (Figure $5 \mathrm{~b}, \mathrm{~d}$ ) is given in Table 2 (Section 6.4). The value of optimal path saving is shown in rows $4\left(\mathrm{I}_{\mathrm{C}}\right.$-impact) and 5 ( $\mathrm{I}_{\mathrm{S}}$-impakt). $\mathrm{D}_{\mathrm{C}}$ is distance PTC Creo MP and $\mathrm{D}_{S}$-distance STEP-NC Machine generated MP.

\section{Simulation of Measuring Path}

Simulation of the MP is based on $[28,33,34]$ and carried out in order to configure the virtual CMM environment for programming and program verification, as well as to avoid collision. Thus, the goal of simulation is to visually inspect the MP in terms of collision for a PW and its tolerance. It is partially based on above mentioned model developed for inspection planning, and at the output it gives a measurement protocol or a list of control data that contains data about coordinates of the measuring points and interposition points. The other part is based on the application of existing software programs for simulation such as PTC Creo and STEP-NC Machine to perform comparison of the MPs lengths.

\subsection{MatLab Simulation}

For verification of the IP2SM4.0 and path simulation, for visual inspection of collision between a measuring sensor and PW, a program was written in MatLab environment. The major goals of the written program is generation of the measurement protocol and the list of control data at the output [28], which are used afterwards in the experiment process planning and as the input for experimental measurements.

The MatLab Simulation was developed using three algorithms, presented in [28], as follows:

- measuring points distribution,

- collision free pat generation, and

- measuring path planning.

As the examples for the verification of MPs on virtual CMM, IFs of plane and cylinder are selected from PW. For both features the unique parameters are defined by ontology knowledge base, e.g., for plane these parameters are $\mathrm{a}, \mathrm{b}$, and $\mathrm{n}$ as well as the homogenous transformation matrix ${ }_{F}^{W} \mathrm{~T}$ that defined the position and orientation of CS of the GF, $\mathrm{O}_{\mathrm{F}}, \mathrm{X}_{\mathrm{F}}, \mathrm{Y}_{\mathrm{F}}, \mathrm{Z}_{\mathrm{F}}$, in accordance with the coordinate frame of $\mathrm{PW} \mathrm{O}_{\mathrm{W}}, \mathrm{X}_{\mathrm{W}}, \mathrm{Y}_{\mathrm{W}}, \mathrm{Z}_{\mathrm{W}}$. Those parameters are used as input data for simulation in a MatLab environment.

The examples of generated initial MPs for plane and cylinder are shown in Figure 6a. Thus generated points are sorted in unique sequences-MP for each IFs. This unique sequence was first visualized in Matlab and then saved in file for loading in CAD/CAM system-PTC Creo. 

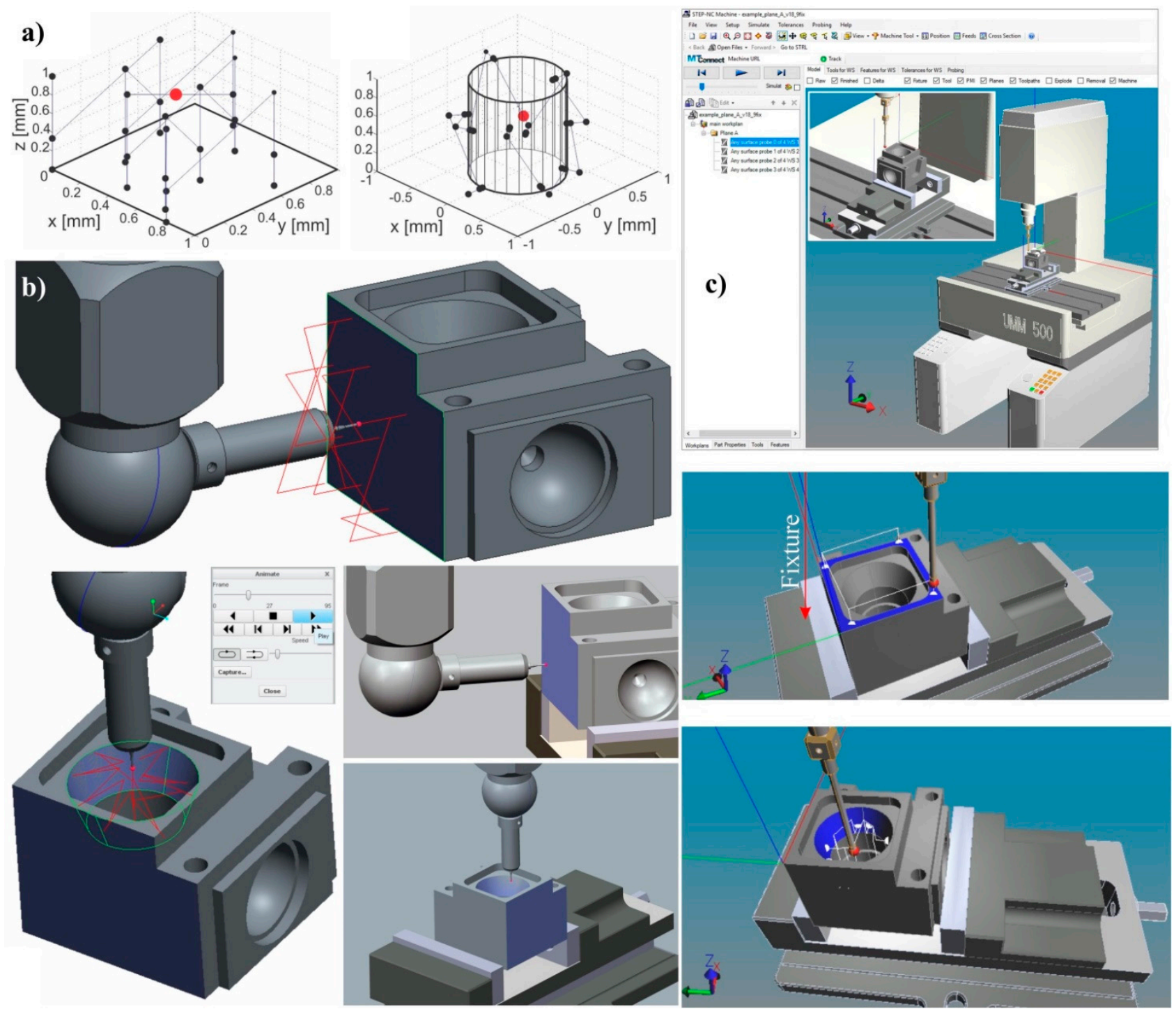

Figure 6. Simulation of measiring path: (a) MatLab simulation, (b) PTC Creo simulation, (c) STEP-NC Machine simulation.

\subsection{PTC Creo Simulation}

The PTC Creo software and the Manufacturing module within it were used to design the MP. According to [33], for creating a MP, the following activities need to be performed: (i) loading of CAD PW; (ii) modeling of CMM; (iii) creating of measurement operation and selecting of task's CS; (iv) choosing of measuring probes; (v) selection of IFs according to tolerance of PW; (vi) choosing of measuring parameters; (vii) import of measurement points, given as a result of the output of the MatLab visualization code; (viii) generation and simulation of a MP on configured VCMM, including a probe.

A model of VCMM is shown in [34]. A detailed VCMM model in PTC Creo software with assembly and kinematic links is presented in [33]. Moving kinematic links (sliders per $\mathrm{X}, \mathrm{Y}, \mathrm{Z}$ axis) allow the movement of CMM components within the permissible limits for each axis and realize the programmed path.

According to [33], to perform simulation it is necessary to define the CS of:

- CMM granite table (MACH_ZERO),

- $\quad$ PW (MACH_ZERO),

- probe holder (TOOL_POINT), and

- probe tip (TOOL). 
Matching the MACH_ZERO CS of PW with the MACH_ZERO granite table CS enables the PW setup on the granite table of configured VCMM during simulation. The same procedure is applied for matching of CSs TOOL and TOOL_POINT for probe setting in a probe holder.

The simulation of MPis applied on a configured VCMM UMM 500 in manufacturing module of PTC Creo software as it shown in Figure 6b. Simulated MP was verified and saved in a CL file (DMIS program) for the purpose of executing the measurement program on real CMM such as UMM 500.

\subsection{STEP-NC Machine Simulation}

The STEP-NC Machine software is used to create a visual measuring system which can include virtual CMM and simulation of the measuring process for generation, verification and monitoring of a MP.

According to [35], STEP-NC Machine simulation based on CMM in this paper consists of the next main steps: (i) creating CAD model of the PW in available CAD system; (ii) defining the CS on the PW (ii) export of this CAD model as a STEP file according to defined coordinate system; (iii) setting up the defined unit before loading of prepared STEP file for inspection into STEP-NC Machine as a PW; (iv) choose the option Probing and Create probing operation; (v) setting of measuring parameters for selected step such as: max. number of probe points, probe clearance, probe along (surface normal or Zaxis), moving between probes, and probe delta distances; (vi) generation of MP and save STEP-NC file; (vii) simulation of MP including head and probe, and (viii) MP simulation on configured Virtual machine UMM500 in STEP-NC Machine, Figure 6c; (ix) export of DMIS file. If STEP-NC file contains machining features or geometric tolerances, STEP-NC Machine can display them.

Based on STEP-NC Machine simulation, the output can generate the DMIS file.

\subsection{Results of Comparison}

The experiment was performed by simulating three types of measurements. The first measurement simulation was performed in PTC Creo software, the second in STEP-NC Machine software and the third measurement in MatLab software according to the ACO model, presented in Section 5.2. The results of the comparison according to the criterion of the minimum path of the measuring sensor, for individual GFs, are given in Table 2. In this case, as mentioned earlier, the required variables are marked as: $D_{C}$ is the measuring path length obtained by PTC Creo; $\mathrm{D}_{S}$ is the measuring path length obtained by STEP-NC Machine; $\mathrm{D}_{\mathrm{O}}$ is the optimized measuring path length obtained with ACO simulated in MatLab software; $\mathrm{I}_{C}$ is percentage of saving of the measuring path length $\mathrm{D}_{\mathrm{O}}$ in relation to $D_{C} ; I_{S}$ is percentage of saving of the measuring path length $D_{O}$ in relation to $D_{S}$.

Table 2. Results of comparison of the three measuring paths for basic GFs.

\begin{tabular}{ccccccc}
\hline & & \multicolumn{3}{c}{ Feature } \\
\cline { 3 - 6 } No. & Name of Path/Impact & Plane & $\begin{array}{c}\text { Trunscated } \\
\text { Hemisphere }\end{array}$ & Circe & Cylinder & $\begin{array}{c}\text { Trunscated } \\
\text { Cone }\end{array}$ \\
\cline { 3 - 7 } & & & 183.6755 & 126.4420 & 228.9870 & 440.1400 \\
1 & PTC Creo $\left(\mathrm{D}_{\mathrm{C}}\right)[\mathrm{mm}]$ & 202.6522 & 165.2395 & 116.2687 & 195.8100 & 362.5900 \\
2 & STEP-NC $\left(\mathrm{D}_{\mathrm{S}}\right)[\mathrm{mm}]$ & 172.4683 & 159.0962 & 110.2460 & 172.2140 & 307.6090 \\
3 & Optimized by ACO $\left(\mathrm{D}_{\mathrm{O}}\right)[\mathrm{mm}]$ & 159.4604 & 13.38 & 12,81 & 24.79 & 30.11 \\
4 & $\mathrm{I}_{\mathrm{C}}=100-\left(\mathrm{D}_{\mathrm{O}} / \mathrm{D}_{\mathrm{C}}[\%]\right)$ & 21.31 & 3.71 & 5.17 & 12.05 & 15.16 \\
5 & $\mathrm{I}_{\mathrm{S}}=100-\left(\mathrm{D}_{\mathrm{O}} / \mathrm{D}_{\mathrm{S}}[\%]\right)$ & 7.54 & & & &
\end{tabular}

A realistic comparison is assured by the basic postulate that the measuring process is the same in all three cases (methods), which can be adjusted so that the parameters have the same value in all three methods. The influence of the start and end points is minimised using such a setting that the parameters of measuring process are the same in all three methods. 
The length of the software measuring paths length $D_{C}$ and $D_{S}$ are taken from the corresponding CL or DMIS file generated by PTC Creo and STEP-NC Machine, while the optimized path length $\mathrm{D}_{\mathrm{O}}$ is the shortest path obtained with the $\mathrm{ACO}$-based model. The software path is obtained by analysing the CL file that shows points used for construction of the measuring path.

Table 2 shows the values of measuring path lengths $\left(\mathrm{D}_{\mathrm{C}}, \mathrm{D}_{\mathrm{S}}\right.$ and $\left.\mathrm{D}_{\mathrm{O}}\right)$ obtained with three simulation methods, as well as the results of comparison. For the observed GFs, the impact $\mathrm{I}_{\mathrm{C}}=100-\left(\mathrm{D}_{\mathrm{O}} / \mathrm{D}_{\mathrm{C}}[\%]\right)$ are in the interval $30.11-12.81 \%$, which presents reduction (save) of the measuring path obtained with $\mathrm{ACO}$ by at least $12.81 \%$. The impact $\mathrm{I}_{\mathrm{S}}=$ $100-\left(\mathrm{D}_{\mathrm{O}} / \mathrm{D}_{\mathrm{S}}[\%]\right)$ are in the interval $15.16-3.71 \%$, which presents reduction (save) of the measuring path obtained with $\mathrm{ACO}$ by at least $3.71 \%$. In accordance with MPE, the results of comparisons were rounded to $2 \mu \mathrm{m}$.

\section{Conclusions}

This paper presents an IP2SM4.0 for Industry 4.0. The described system is based on a digital (towards smart) CMM suitable for accomplishing smart metrological processes in accordance with metrological tasks of the concept Industry 4.0. Generally, metrological tasks depend on geometrical and metrological complexity of PW and it is very important to verify the smart measuring process before the execution of measurement and MP on CMM. The CMMs are recognized as a flexible element of production metrology, and they are applicable for a wide range of metrological tasks. It is for this reason that CMM is used in this paper as a measuring device.

In the present paper, the verification of MP, based on IP2SM4.0, is first visualized in MatLab, then through simulations in the STEP-NC and CMM modules of PTC Creo. The simulation of the MP was realized on the configured VCMM UMM 500. Output from the simulation on virtual CMM generated MP was saved in the CL file (DMIS program). When this file is generated, the developing of a postprocessor leaves the possibility for creating a control data list for different CMMs.

A comparison of three types of simulated measurement paths on VCMMs was performed. The optimal measuring path was compared with (i) the PTC Creo programmed measuring path, and (ii) the automatically generated measuring path in the STEP-NC Machine software for a specially designed PW for this purposes. The optimal measuring path is compared with the PTC Creo measuring path on a CMM and with the automatically generated measuring path in the STEP-NC Machine, for the observed PW. A comparison between the optimal path obtained by ACO and the PTC Creo programmed path shows improvement, i.e., reduction of the measuring path length per GFs in the interval from $12.81 \%$ to $30.11 \%$. Also, the optimal path obtained by ACO is shorter per GFs from $3.71 \%$ to $15.16 \%$, that the path obtained with STEP-NC Machine software, using the same parameter settings for both methods.

The advantage of this approach is to reduce the measurement time by optimization of the measurement path for measurement of complex PWs. If it is known that in measurements on a CMM the measuring path length given in Table 2 is directly proportional to time, mentioned optimizations reduce length of measuring path and thus reduce measuring time and raising work productivity on a CMM in the inspection planning phase and later in the measurements execution phase. Also, the advantages of IP2SM4.0 involve open architecture, flexibility and adaptability to various measurement strategies, from conventional to the latest, such as the STEP-NC Machine software strategy. On the other hand, commercial software packages do not have a completely open architecture. IP2SM4.0 automatically generates the measuring path, eliminating operator's intuition and experience to a large extent, which is in the context of Industry 4.0 one of the prerequisites for its successful application.

Conducted research in this paper is an answer to the industry's requirement as its maintenance of the permanent, required level of inspection by modeling and simulation of the part of activity performed by an inspection planner. On the basis of proposed 
methodology, directions of future research would embrace extension to non-prismatic machine parts (parts with free-form measuring surfaces) and towards the development of a digital twin for measurements on a CMM.

Author Contributions: S.M.S.: conceptualization, methodology, software, validation, investigation, resources, writing — original draft preparation, visualization; V.D.M.: conceptualization, methodology, investigation, resources, writing - review and editing, visualization, supervision; A.G.: conceptualization, methodology, software, validation, investigation, resources, writing — original draft preparation, visualization; J.S.: conceptualization, methodology, investigation, resources, writing-review and editing, visualization, supervision. N.M.D.: conceptualization, methodology, investigation, resources, writing - review and editing, visualization, supervision. All authors have read and agreed to the published version of the manuscript.

Funding: This research received no external funding.

Institutional Review Board Statement: Not applicable.

Informed Consent Statement: Not applicable.

Data Availability Statement: The data presented in this study is available within this article.

Acknowledgments: The presented research was supported by the Ministry of Education, Science and Technological Development of the Republic of Serbia under Grant No. 451-03-9/2021-14/200105.

Conflicts of Interest: The authors declare no conflict of interest.

\section{Abbreviations}

The following abbreviations are used in this manuscript:

AI artificial intelligence

ACO ants colony optimization

AP application protocols

BDA big data analytics

CAI computer aided inspection

CAD computer aided design

CAM computer aided manufacturing

$\mathrm{CMM}$ coordinate measuring machine

CPS cyber physical system

CP2M cyber physical manufacturing metrology

CP3M cyber physical manufacturing metrology model

CL cutter location

CS coordinate system

DMIS dimensional measuring interface standard

DML dimensional markup language

ERP enterprise resource planning

EO engineering ontology

FAD feature approach direction

GA genetic algorithm

GF geometric feature

IoT Internet of Things

IT information technology

IIoT industrial internet of things

IP2SM4.0 inspection planning system as a support of manufacturing metrology 4.0

IGES initial graphics exchange specification

MES manufacturing execution system

MM4.0 manufacturing metrology

MP measuring path

OWL web ontology language

PAD probe approach direction

PW prismatic workpiece

STEP standard for the exchange of product model data 


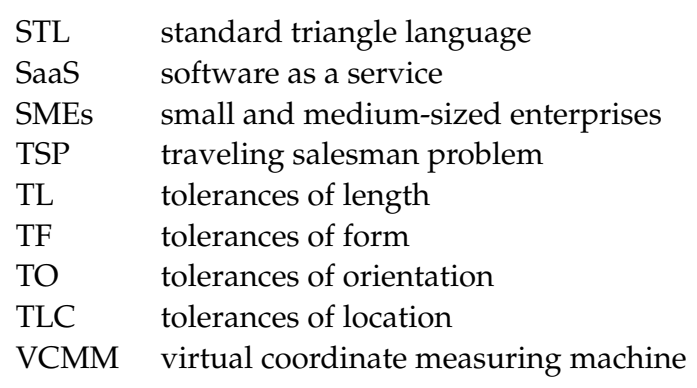

\section{References}

1. Zhong, R.Y.; Xu, X.; Klotz, E.; Newman, S.T. Intelligent manufacturing in the context of industry 4.0: A review. Engineering 2017, 3, 616-630. [CrossRef]

2. Lee, J.; Bagheri, B.; Kao, H.-A. A Cyber-Physical Systems architecture for Industry 4.0-based manufacturing systems. Manuf. Lett. 2015, 3, 18-23. [CrossRef]

3. Stojadinovic, S.M.; Majstorovic, V.D.; Durakbasa, N.M. Toward a cyber-physical manufacturing metrology model for industry 4.0. Artif. Intell. Eng. Des. Anal. Manuf. 2021, 35, 20-36. [CrossRef]

4. RWTH Aachen Campus. Available online: https://i40mc.de/en (accessed on 20 April 2020).

5. Industry 4.0 and the Fourth Industrial Revolution Explained. Available online: https://www.i-scoop.eu/industry-4-0 (accessed on 20 April 2020).

6. Majstorovic, V.D.; Durakbasa, N.; Takaya, Y.; Stojadinovic, S. Advanced Manufacturing Metrology in Context of Industry 4.0 Model. In Proceedings of the Recent Advances in Computational Mechanics and Simulations, Belgrade, Serbia, 4-7 June 2019; pp. 1-11.

7. Majstorovic, D.V.; Stojadinovic, S. Cyber Physical Manufacturing Metrology NEWTECH 2020 IOP Conf. 2020 Series: Materials Science and Engineering; IOP Publishing: Bristol, UK, 2020.

8. Yong, Y.; Kathryn, E.S.; Dongni, L. The evolution of production systems from Industry 2.0 through Industry 4.0. Int. J. Prod. Res. 2018, 56, 848-861.

9. $\quad \mathrm{Lu}, \mathrm{Y} . ; \mathrm{Xu}, \mathrm{X}$.; Wang, L. Smart manufacturing process and system automation-A critical review of the standards and envi-sioned scenarios. J. Manuf. Syst. 2020, 56, 312-325. [CrossRef]

10. Lu, Y.; Huang, H.; Liu, C.; Xu, X. Standards for Smart Manufacturing: A review. In Proceedings of the 2019 IEEE 15th International Conference on Automation Science and Engineering (CASE), Vancouver, BC, Canada, 22-26 August 2019; pp. 73-78.

11. Takaya, Y. Strategic Vision for Smart Machining Tool and Measuring Instrument. NTN Tech. Rev. 2018, 86, 20-41.

12. Lee, C.-H.; Chen, C.-H.; Lin, C.; Li, F.; Zhao, X. Developing a Quick Response Product Configuration System under Industry 4.0 Based on Customer Requirement Modelling and Optimization Method. Appl. Sci. 2019, 9, 5004. [CrossRef]

13. Lazzari, A.; Pou, J.-M.; Dubois, C.; Leblond, L. Smart metrology: The importance of metrology of decisions in the big data era. IEEE Instrum. Meas. Mag. 2017, 20, 22-29. [CrossRef]

14. Ana, P.C.-M.; Horacio, A.-G.; Darío, G.-L.; Maria, F.M.-A.; Pedro, D.U.C.; Pedro, A.O.C.; Thomas, R.K.; Emilio, G.C. Connectivity as a Design Feature for Industry 4.0 Production Equipment: Application for the Development of an In-Line Metrology System. Appl. Sci. 2021, 11, 1312.

15. Sander, L.; Norbert, G. A factory operating system for extending existing factories to Industry 4.0. Comput. Ind. 2020, 115, 103128.

16. Tariq, M.; Paul, S. Industry 4.0: Adoption challenges and benefits for SMEs. Comput. Ind. 2020, 121, 103261.

17. Alberto, C.; Miguel, A.S.; Cristina, G.G. Industry 4.0 HUB: A Collaborative Knowledge Transfer Platform for Small and Me-diumSized Enterprises. Appl. Sci. 2021, 11, 5548.

18. Szilárd, J.; Adrienn, S.; Tibor, H.; Tibor, C.; János, A. Development of manufacturing execution systems in accordance with Industry 4.0 requirements: A review of standard- and ontology-based methodologies and tools. Comput. Ind. 2020, 123, 103300.

19. Sameer, M.; Muztoba, K.; David, R.; Thorsten, W. A critical review of smart manufacturing \& Industry 4.0 maturity models: Implications for small and medium-sized enterprises (SMEs). J. Manuf. Syst. 2019, 49, 194-214.

20. Dan, L.; Asa, F.-B.; Dan, P. Current and future Industry 4.0 capabilities for information and knowledge sharing-Case of two Swedish SMEs. Int. J. Adv. Manuf. Technol. 2019, 105, 3951-3963.

21. Majstorović, V.; Mačužić, J.; Šibalija, T.; Živković, S. Cyber-Physical Manufacturing Systems-Manufacturing Metrology Aspects. J. Proc. Manuf. Syst. 2015, 10, 9-14.

22. Berthold, J.; Imkamp, D. Looking at the future of manufacturing metrology: Roadmap document of the German VDI/VDE Society for Measurement and Automatic Control. J. Sens. Sens. Syst. 2013, 2, 1-7. [CrossRef]

23. Majstorovic, V.D.; Stojadinovic, S.M.; Sibalija, T.V. Development of a knowledge base for the planning of prismatic parts inspection on CMM. Acta IMEKO 2015, 4, 10. [CrossRef]

24. Stanford University, Protégé. Available online: http:/ / protege.stanford.edu/ (accessed on 5 April 2012).

25. Stojadinović, S.M.; Majstorovic, V. Developing engineering ontology for domain coordinate metrology. FME Trans. 2014, 42, 249-255. [CrossRef] 
26. Stojadinovic, S.; Majstorovic, V. Towards the Development of Feature-Based Ontology for Inspection Planning System on CMM. J. Mach. Eng. 2012, 12, 89-98.

27. Stojadinović, S.M.; Majstorović, V.D. An Intelligent Inspection Planning System for Prismatic Parts on CMMs; Springer Science and Business Media LLC: Berlin, Germany, 2019.

28. Stojadinovic, S.M.; Majstorovic, V.D.; Durakbasa, N.M.; Sibalija, T.V. Towards an intelligent approach for CMM inspection planning of prismatic parts. Measurement 2016, 92, 326-339. [CrossRef]

29. Rice, O.; Nyman, R. Efficiently Vectorized Code for Population Based Optimization Algorithms; UCL Department of Computer Science: London, UK, 2013.

30. Stojadinovic, S.; Majstorovic, V.; Durakbasa, N.; Sibalija, T. Ants Colony Optimization of the Measuring Path of Prismatic Parts on a CMM. Metrol. Meas. Syst. 2016, 23, 119-132. [CrossRef]

31. Dorigo, M.; Stützle, T. Ant Colony Optimization; The MIT Press: Cambridge, MA, USA, 2004.

32. Dorigo, M.; Blum, C. Ant colony optimization theory: A survey. Theor. Comput. Sci. 2005, 344, 243-278. [CrossRef]

33. Stojadinovic, M.S.; Zivanovic, S.; Slavkovic, N. Verification of the CMM Measurement Path Based on the Modified Ham-mersly's Algorithm. In Proceedings of the 12th International Conference on Measurement and Quality Control-Cyber Physical Issue, Belgrade, Serbia, 4-7 June 2019; pp. 25-38.

34. Sładek, J.; Gaska, A.; Olszewska, M.; Kupiec, R.; Krawczyk, M. Virtual coordinate measuring machine built using Laser Tracer system and spherical standard. Metrol. Meas. Syst. 2013, 1, 77-86. [CrossRef]

35. STEP Tools. Available online: https://www.steptools.com (accessed on 11 February 2021). 